\title{
The Influence of Social Media on Youth Leisure in Rongo University
}

\author{
Charles Nyambuga* and Josphat Ogweno
}

Department of Communication and Media, Maseno University, Kisumu, Kenya

\begin{abstract}
The past has witnessed a growing interest among researchers in exploring the linkages between the media attitudes and behaviours of youth in Kenya. In the context of increasing use of social media, research on the influence of social media on youth leisure is significantly low. Very few studies have explored media use patterns among youth in terms of their media preferences and active leisure participation. A recent review of youth use of social media recommends the need for research aimed at understanding how the social media influences youth and how youth allocate time in active leisure as they use social media. Therefore this research seeks to find out the influence of social media on youth leisure in Rongo University College Town Campus.
\end{abstract}

Keywords: Social media; Media; Communication; Conceptual synergy

\section{Introduction}

Youth today are living in what Tam et al. [1] provocatively termed 'The Global Village' all over the world youth seem to be spending their leisure time in front of television and computer screens. As the social media use among the youth increases, it causes a wide scale realignment of their leisure behaviour. Considerable attention and concern are focused on how they use the social media because they are seen as the 'digital generation,' at the vanguard of new skills and technologies, yet they could also be vulnerable and at risk of the influence of social media. Little research has been conducted to show the link between social media and youth leisure. The focus has largely been on the positive role of the social media such as informing, persuading and entertaining this leaves out the more negative roles of the social media such as creating negative behaviour on the youth and denying them enough time for active leisure. Safko and Brake [2] state that Social Media refers to activities, practices, and behaviours among communities of people, who gather online to share information, knowledge, and opinions using conversational media. Conversational media covers the webbased applications that make it possible to create and easily transmit content in form of words, pictures, videos, and audios.

Social media, internet and cell phones are growing rapidly in terms of consumers and service providers. From October to December, 2010, mobile subscriptions in Kenya grew by 12 per cent from 22.3 million to 24.96 million subscribers, which was the highest growth rate recorded that year, as evidenced by Safaricom's huge profits [3]. The Digital Life Survey, a report by TNS Research International (2009) in Kenya, found that 60 per cent of respondents use their handsets to access the internet, compared with 29 per cent using PCs at home, 33 per cent using PCs at work and 41 per cent accessing the internet in cyber cafés. The leading activities on mobile internet are social networking (67\% of users) and accessing e-mails (54\%) [4,5]. The internet as an innovative force could have profound influence on youths, so in order to understand the place of social media in the lives of the youth requires that we avoid a purely deterministic interpretation and recognize its influence [6]. With the increasing penetration of social media in Kenya, it may influence young people's allocation of time spent with various media, as well as how it could be used to fulfill their leisure time [7-9].

\section{Statement of the Problem}

Social media represents a wide world of opportunity for the youth that could be filled with both good and bad influence and may have a wide ramification for their active leisure [10]. Considerable attention and concern are now focused on how the youth use the social media because they are seen as the 'digital generation,' and exposed to new skills and technologies, yet they could also be vulnerable and at risk of the influence of social media [10]. Little research has been conducted to show the link between social media and youth leisure. The focus has largely been on the positive role of the social media such as informing, persuading and entertaining this leaves out the more negative roles of the social media such as creating negative behaviour on the youth and denying them enough time for active leisure. This research therefore investigated the influence of social media on youth leisure with a view to establishing how the mass media mediates messages among youths in the face of the changing communication patterns as social media becomes a significant feature of adolescents' lives [11].

\section{Research questions}

- Which social media do the youth access in Rongo University College Town Campus?

- How do the youths in Rongo University College Town Campus use social media to influence their leisure activities?

\section{Research objectives}

In order to investigate the influence of the new media on youth leisure this study had the following research objectives:

- To investigate which social media youth in Rongo University College access.

- To examine how youths in Rongo University College use social media to satisfy their leisure time.

\section{Scope and limitations of the study}

The study was conducted in Rongo district, Migori County and

*Corresponding author: Charles Nyambuga, Department of Communication and Media, Maseno University, Kisumu, Kenya, Tel:+254 721209397; E-mail: cnyambuga@yahoo.com

Received July 16, 2014; Accepted August 18, 2014; Published August 25, 2014

Citation: Nyambuga C, Ogweno J (2014) The Influence of Social Media on Youth Leisure in Rongo University. J Mass Communicat Journalism 4: 223 doi:10.4172/2165-7912.1000223

Copyright: (C) 2014 Nyambuga C, et al. This is an open-access article distributed under the terms of the Creative Commons Attribution License, which permits unrestricted use, distribution, and reproduction in any medium, provided the original author and source are credited. 
majorly focused on youth located within the District specifically Rongo University College town campus in Kenya. All the youths were chosen on the basis of their frequent use of the social media. The study was limited to selected social media i.e. Facebook and Tweeter this was because they were widely used and niches of active leisure pursuits, such as gaming, hacking and chatting. This study was also limited by the fact that the population analyzed was all from the same area of study thus may not represent a national setting but the study was strengthened by the fact that the targeted Rongo University College have a youth population selected from all over Kenya.

\section{Significance of the study}

This study hoped to offer an analysis on the influence of social media on youth leisure and can be used by media specialists to analyze issues of interest to youth in order to fully understand the role of mass mediated messages in the lives of youth and be able to reveal much about how communication patterns are changing as adolescents incorporate social media into their lives [12]. Technology has the potential to force people to mould themselves according to its user fracture. Therefore, it is necessary and indispensable to understand the use of technology for the purpose of recreation and leisure by the youth and consequently be used by the policy makers to improve on National youth policy on youth recreation and leisure in Kenya. In Kenya, the number of youth who access the social media is steadily increasing [4]. This means that there are an increasing number of youths who access the social media. It is therefore important to establish the possible influence of the wider access to social media on the leisure activities of the youths thus this study can be used by policy makers in Kenya to fulfill Vision 2030 on accessibility to internet by all youth.

The study was further significant because it may complete knowledge to the role of media in a diverse society in youth empowerment. Social media could have both intended and unintended roles to youth development. This study could significantly contribute to knowledge on factors responsible for the gap between intended and unintended roles of the media in a diverse society characterized by dynamic youth behaviour. This research was carried out to determine the linkage between social media content and the youth preferences to leisure activities hoping that this knowledge would assist in re-framing social media content in a manner that could promote proper choice of time allocation by the youth in their leisure activities.

\section{Conceptual frame work}

In order to explain the influence of Social media on youth leisure, this study used theories of leisure to explain why the youth do not participate in active leisure, and media theories exploring how the social media influenced their leisure activities and finally drew a conceptual synergy [13].

\section{Stimulation Theory}

The Stimulation Theory argues that people need a certain level of physical and mental activity. Since some individuals strive to maintain an optimal state of stimulus, they will attend physical activities [14] This theory suggests that, whenever media content arouses a student, he or she would like to keep that arousal and pursue further excitement through real exertion of physical energy. Based on the above theory, a person who is more stimulated by media exposure is more likely to heighten his or her arousal level and thus will be more likely to seek his or her optimal state of stimulus from relatively competitive physical activities. In other words, this theory suggests that watching Television, viewing videos and playing video games can stimulate people's emotion to indulge in more active behaviour. People who spend more time watching Television, videos and Digital Video Discs or playing computer/video games are more likely to engage in active leisure activities. Russell [14] argues that a common criticism of watching TV is that it replaces more active leisure. This is backed by Robinson [15] who found that some of the early substitutes of TV, such as listening to radio, visiting friends, doing housework and reading newspapers have continued to decline.

\section{Uses and gratification theory}

The uses and gratification theory proposed by Blumler and Katz [16] assumes that media users are goal-oriented. They play an active role in selecting and using the media to best fulfill their individual needs. The uses and gratification theory shifts the emphasis of media communication studies from an effect perspective to an audience perspective. The uses and gratification theory assumes that media users have a variety of choices to satisfy their needs and each medium can have different functions. Uses and gratification theory is now widely accepted for nearly all kinds of mediated communication tools. For example, the uses and gratification theory was adopted in the study of how adolescents used new technology including Video Cassette Recorder [17], the impact of VCRs and cable TV on passing-time and companion gratification from watching television [18]. Uses and Gratification approach is essential to this study that seeks to $c$ onfirm or refute the assumed influence of the social media on youth leisure time [19]. Applied to this study, this approach views youth as active participants who not only consume all other forms of media but also it assumes that they only select specific types of media that suit their desired leisure and gratifies their individual needs [19]. The theory also presumes that the youth do not solely rely on traditional forms of media as their only source of entertainment and other leisure activities, but also depend on other sources outside the media [19].

\section{Conceptual synergy}

The Saturation theory and Uses and Gratification theories are closely related. These theories were used in this study to explain how the social media could influence the youth leisure time, and how these theories were applied within the Leisure social context. This study offered a point of analysis of how the social media influences youth allocation of time for their physical leisure guided by the two theories. The social media as characterized by the two theories mentioned above has the capacity to influence the use of various media by the youth to satisfy their leisure. The Stimulation Theory argues that people need a certain level of physical and mental activity. The uses and gratification theory assumes that media users have a variety of choices to satisfy their needs and each medium can have different functions. In essence, through this research, it was evident that models of Saturation and Uses and Gratification theories link media content as the unit of observation to audience characteristics [20]. These theories were therefore critical in providing a foundation for further analysis on the influence of social media to youth mediated messages, as each of them explained the social media and possible impacts on Youths.

\section{Literature Review}

\section{Introduction}

This section discusses available literature relating to the study objectives. The themes reviewed included youth and time allocation in Social media and Uses of social media to satisfy leisure.

\section{Youth and media accessibility}


The exponential growth of the Social Media use globally has given rise to a number of challenges. One of these challenges is that, different kinds of information have become available to everybody who has access to the social media. Gross [21] mentions the fact that youth have access to the social media but it is not always known how the use of the social media influences their well being and development. The youth are generally enthusiastic adopters of the Internet for communication, entertainment and education. Youth regard the Internet as a flexible medium, and research has identified (in rankorder) the following motives for using it: affinity with computers, information, entertainment, boredom avoidance, online social interaction, and off-line social interaction [22]. Chesley [23] examined why people use ICTs for communication the author concluded that people use computing and communications technologies [24] because they need them for work or because they think these new devices will help with family needs, subject, of course, to resource constraints. In Kenya the number of Internet users per 100 young people has risen over the years while that of fixed broadband subscribers has remained constant [25]. A report by David j McKenzie [26] on Youth, ICTS and Development (2011) reveals that the new millennium saw extremely rapid increases in internet, mobile phone, and computer use in Kenya. According to Consumer Insight (2009), computer use among 7-19 year olds increased from $33 \%$ in 2005 to $38 \%$ in 2007 and to $41 \%$ in 2009 . Computer use increased with age [27]. Among 7-10 year olds only $23 \%$ had used a computer, $36 \%$ among $11-14$ year olds, $47 \%$ among $15-17$ year olds and 57\% among 18-19 year olds. According to Consumer Insight, the highest facilitator of internet access among 7-19 year olds is school/college (45\%) followed by cyber cafés $(33 \%)$ and home $(29 \%)$. The workplace for this age group facilitates only 3\%. Among 25-44 year olds, access is mostly facilitated by the office/ workplace (56\%) followed by cyber cafés (12\%) and mobile phones (10\%) Makanja [25]. The main back-up source is the mobile phone (58\%), cyber cafés (36\%) and home computers (33\%) [28].

\section{The use of new media to satisfy youth leisure}

Morozov [29] credited Twitter with enabling revolution by youth in Iran alongside other social media implicated in ongoing revolutions throughout the Middle East. Facebook has become a household word around the world. Every day, Internet users around the world carve out niches of active leisure pursuits, such as gaming, hacking, chatting, tending to virtual farms, designing pixilated homes through video-logging and photo-sharing. It is clear that the social web, which constitutes a fundamental component of a seemingly unstoppable move towards perpetual connectivity as a way of life in many countries, should not be underestimated. However, web-based leisure activities should equally not be seen as profoundly distinct, or wholly set apart, from their offline context [30].

\section{Research Methodology}

\section{Introduction}

This section discusses the research methodology that was adopted. Specifically, it outlines the delimited study area, research design, target population, sampling design, research instruments, data analysis, and ethical considerations.

\section{Research design}

The descriptive research design was used in this study. According to Mugenda and Mugenda [31], descriptive design is a self reporting study, which brings out quantifiable information from the sample. Descriptive design was used because it allowed for extensive data collection on a large population as was witnessed in the study sample in Rongo University College. The design enabled the researcher to establish the extent at which the youth were influenced by social media in Rongo University College within the context of the independent and dependent variables [32].

\section{Study area}

The study was conducted at Rongo University College, a constituent college of Moi University, which is one of the newly created Universities in Kenya formed, vide Education Act and Presidential declaration in (2008) and it is in Migori County Rongo District. This location will give a representation of youth who access the new media.

\section{Study population}

The study will seek to obtain research data from a total of 225 youth in Rongo University College. The population consisted of youth of between 18-35 years and the female youth were100 and male were 125 . The population was selected from the Department of communication and media studies because they understood well communication dynamics in regard to the social media. The study population also engaged in active sporting activities such as, Hockey, football, basketball and handball. The population was arrived at on the basis that it was dynamic population with a representation of youth from all over Kenya and it also consisted both male and female youth [33].

\section{Sample procedure}

Random sampling was used to sample the size for the study that consisted 144 youth from Rongo University College; this was a population of 225 youth in the University as shown in the sampling procedure. Among the respondents, 58\% were males and $42 \%$ were females. The population in Rongo University College consisted of youth coming from all over Kenya. The study populations for this research were youth who access social media. Specific sample area, Rongo University College was purposively selected based on the fact that it has youth who access social media.

\section{The sample size}

A convenience sample of youths was recruited from Rongo University College town campus. The questionnaire was administered by a sample of students $(\mathrm{N}=144)$. To ensure voluntary and anonymous participation, a passive consent letter was attached to the front of the questionnaire. The study adopted a two - stage sampling. The first step involved stratification of the location of the study. Rongo University College was the unit of analysis in this study. In this study the researcher used both purposive sampling and simple random sampling techniques in arriving at the sample size for the study. Therefore, a total of 80 male students participated in the study drawing all the participants from the Faculty of Communication. In addition, there were a total of 64 females. This purposeful selection was made both to find regular users of the social media and to balance their views as [34] advises to use purposeful sampling as quoted. Random sampling was used to acquire the desired sample to select 144 youth from Rongo University. Youth in the College were preferred because they tended to be mostly exposed to the new media and had a national representation. All the sampled youth in the College were asked to complete the questionnaires. The following formula advanced by Yamane and Supported by Morgan, was used to calculate sample size (Table 1).

\section{As shown below}

$\mathrm{n}$ is the required sample size. 


\begin{tabular}{|l|l|l|}
\hline Study strata & Population size & Stratum sample size \\
\hline Youth at Town campus & 144 & $144 / 225 \times 225=144$ \\
\hline Total & 100 & 80 \\
\hline
\end{tabular}

Table 1: Sampling matrix.

Source: Office of the registrar Rongo University College

$\mathrm{N}$ is the population size.

$\mathrm{e}$ is the level of precision i.e. 0.05 .

\section{Instruments of data collection}

Data collection was qualitative through use of Simple Random Selection. Prior to the data collection, ethical approval was sought from SGS. Pre-testing of the instruments was carried out in the college based on the ability to clearly give the information on how to collect the information and type of funding. The study adopted both interviews and questionnaires. The interview guides contained items covering all the objectives of the study.

\section{Interviews}

Semi structured interviews were conducted and the interviewers investigated how the youths allocated their time across the social media to various activities. The research interviewed respondents in order to validate the information collected using the questionnaires. To ensure comprehensive examination on the influence of Social media on youth leisure the interview schedule was used.

\section{Questionnaires}

The questionnaire consisted of two parts. The first part of the questionnaire focused on the media accessed by youth in Rongo University such as phone, laptop and desktop. Respondents' time allocation to the media was measured by asking, "How much time on average do you spend with each medium every day?" and uses of social media to satisfy their leisure activities. The second part of the questionnaire asked about the contexts of the Internet usage. Respondents were asked about their access to the social media and its uses to satisfy their leisure. Questions were asked about how the respondents used the social media for specific purposes. Lists of five usages of the social media were included in the study such as having chatting with friends on phone, accessing new sites and hiking. A twopoint scale $(1=y e s ; 2=$ no) was employed to measure the usage of the social media and demographic characteristic was also collected [35].

\section{Primary data}

Primary data was collected through use of questionnaires and interviews.

\section{Secondary data}

Secondary data was obtained from the Rongo University Library and other libraries to gather materials relevant for the study. The library and the internet were vital sources of secondary information for the study. Secondary data was vital to back up the primary data as well as provide insights which primary data alone could not provide.

\section{Data analysis and presentation}

Qualitative data from open ended questionnaires and transcripts from the interviews were analyzed using SPSS. The narrative data was read carefully for better understanding and quality considerations, data was then organized as per questions then analysed across all the respondents in order to identify consistencies and differences.
Thus data was analyzed using Statistical Package for Social Sciences (version 20.0 for windows) with descriptive measures. After all data was collected, the researcher conducted data cleaning, which involved identification of incomplete or inaccurate responses, which were corrected to improve the quality of the responses. After data cleaning, the data was coded and entered in the computer for analysis using the Statistical Package for Social Sciences (SPSS) version 20.0.

\section{Validity}

With any research, measurements and analysis need to be both valid and reliable. According to Rubin et al., measurement validity refers to measuring what is intended to be measured, and suggests truthfulness. If the index, text, or scale were used to measure a particular construct, then the measure should include questions about all aspects of the construct. Referred to as content validity, these measures should sample or represent all ideas or areas in the conceptual space of the definition represented in the measure [36]. The measure should also relate to similar measures or predict future behaviour. Thus the tools of this study were pre- tested to check their efficacy. The questionnaires were administered on a pilot basis to the respondents. The pilot phase involved 50 questionnaires to that group of respondents. Their feedback was consolidated to adjust the questionnaire and make it more precise and user-friendly. The results were comparable to those of the actual data that were collected for the main research stage. All the objectives of this study were covered by the tools of the research, and the content validated by the same.

\section{Reliability}

Reliability in a study ensures that its results are dependable and consistent. It indicates that the same thing will occur under identical or similar conditions. "Measurement reliability means that the numerical results produced by an indicator do not vary because of characteristics of the measurement process or measuring instrument itself' Neuman [36]. This equivalence reliability applies when a construct is measured with multiple specific methods. If the different indicators point to the same construct, then a reliable measure will give the same results with multiple indicators. Validity and reliability increased the internal validity of a research study and ensured that no one derived other possible interpretations from the results. The test-retest method of reliability check was used to ascertain the functionality and clarity of the questionnaire. After the pre-test, corrections were undertaken, and the reliability and validity index calculated.

\section{Ethical issues}

Permission in writing to interview the youth in the University was granted by the college administration [37]. The researcher also sought permission to use any programme in this study. Accordingly, this study also sought permission from the study informants individually before participation. No one was forced to neither participate nor disclose information they did not wish to divulge. The researcher also availed the transcribed findings to the respondents and they verified the information gathered from them. It was also agreed that the data be used for academic purposes. The researcher also sought permission from Maseno University to be allowed to carry out the study.

\section{Data Presentation, Analysis and Discussions}

\section{Demographic characteristics of respondents}

Included in the study were 80 male youth, 64 female youth, in Rongo University where a total sample of 144 youth was taken. The 
Citation: Nyambuga C, Ogweno J (2014) The Influence of Social Media on Youth Leisure in Rongo University. J Mass Communicat Journalism 4: 223 doi:10.4172/2165-7912.1000223

Page 5 of 7

respondents responded fully as depicted in the return rate of the questionnaires.

\section{Demographic characteristics of youth respondents' by gender}

The study realized 144 youth respondents. Among them the study had a population of (80) male respondents constituting 55.6 percent of the total youth respondent population who access the social media. Besides, the study had 64 female youth respondents that formed part of the study, constituting 44.4 percent of the total respondent population accessing social media (Table 2 ).

\section{Media access by the respondents}

The first research question sought to find out the media accessed by the respondents. To determine this, the respondents were asked to rate the frequency of use of the media enumerated in the questionnaire, to which they responded as shown in (Table 3) where it emerged that, the most frequently used media by the respondents was phones. Data in (Table 3) below indicate that more respondents of both sexes accessed the phone at ( 97.2 percent) and (2.8 percent) accessed laptops respectively. The percentages for access to the ipad and desktop were $0 \%$. This showed that there are no respondents who accessed the ipad and desktops but a great percentage accessed both the phone and the laptop. These results were consistent with findings of Schoulen on adolescent online self-disclosure and self-presentation research. Thus the respondents accessed phone and laptops to a greater percentage (Table 3).

\section{Social Media application accessed by the respondents}

From the following figure, the respondents accessed their contents from Facebook and Twitter more. i.e. 84\% of the respondents accessed Facebook contents while $16 \%$ accessed Twitter. This indicated that Facebook and Twitter were the preferred areas to the respondents to access contents that could easily satisfy their leisure time and activities (Table 4).

\section{Hindrances the respondents face in accessing the contents in their preferred media}

The study indicated in (Table 3 ) that $3.5 \%$ of the respondents agreed that they had hindrances to accessing the contents on Facebook and twitter. In addition, $96 \%$ of the respondents confirmed that they had no hindrances to accessing Facebook and twitter contents. The finding also ascribe to the findings of Ellen Johanna [38]. Who advanced that 71 percent of respondents easily access the contents on social media

\begin{tabular}{|c|c|c|}
\hline & Frequency & Percent (\%) \\
\hline Male & 80 & $55.60 \%$ \\
\hline Female & 64 & $44.40 \%$ \\
\hline Total & 144 & $100.00 \%$ \\
\hline
\end{tabular}

Table 2: Demographic characteristics of respondents' by gender.

\begin{tabular}{|c|c|c|c|}
\hline & & Frequency & Percent \\
\hline \multirow{3}{*}{ Mode of access } & Phone & 140 & 97.2 \\
\hline & Laptop & 4 & 2.8 \\
\hline & Total & 144 & 100 \\
\hline
\end{tabular}

Table 3: Media access by the respondents.

\begin{tabular}{|l|c|c|}
\hline Media applications accessed by youth & Frequency & Percent \\
\hline Facebook & 142 & 98.6 \\
\hline Twitter & 2 & 1.4 \\
\hline Total & 144 & 100 \\
\hline
\end{tabular}

Table 4: Social media applications accessed by youth.

\begin{tabular}{|l|c|c|}
\hline Hindrances in Accessing Content & Frequency & Percent \\
\hline Yes & 5 & 3.5 \\
\hline No & 139 & 96.5 \\
\hline Total & 144 & 100 \\
\hline
\end{tabular}

Table 5: Hindrances to access of contents by the respondents.

\begin{tabular}{|l|c|c|c|}
\hline \multicolumn{2}{|l|}{ Chatting On Phone } & Frequency & Percent \\
\hline Response & Yes & 144 & 100 \\
\hline Accessing Sites & & Frequency & Percent \\
\hline Response & Yes & 144 & 100 \\
\hline Playing Games & & Frequency & Percent \\
\hline Response & Yes & 144 & 100 \\
\hline Hiking & & Frequency & Percent \\
\hline Response & Yes & 144 & 100 \\
\hline
\end{tabular}

Table 6: Leisure activities in which Respondents involved.

\begin{tabular}{|l|l|c|c|}
\hline \multicolumn{2}{|l|}{ Does Internet Enable Accessibility } & Frequency & Percent \\
\hline Internet & Yes & 144 & 100 \\
\hline Internet Assisting Accessing New Sites & Frequency & Percent \\
\hline Internet & Yes & 144 & 100 \\
\hline Internet Assisting Hiking & Frequency & Percent \\
\hline Internet & Yes & 144 & 100 \\
\hline
\end{tabular}

Table 7: Internet aided leisure activities.

without any hindrances in school to advance their interest (Table 5).

\section{Use of social media to satisfy leisure}

This section presents results and discussions to answer the second research question on use of social media to satisfy youth leisure. The variables under consideration were leisure activities involved, uses of internet to access leisure and time taken in the preferred leisure (Table $6)$.

The study found that out of the respondents, $100 \%$ chatted on phone with friends, while $100 \%$ accessed new sites. $100 \%$ played computer games and none went for hiking. Therefore, a big percentage participated in passive leisure neglecting active leisure for example hiking and playing games.

Use of internet to access preferred leisure activities: The study indicated in (Table 7) that 100 percent of the respondents agreed that internet assisted to access their preferred leisure activity. In addition, 100 percent of the respondents affirmed that internet enabled the respondents to access the following leisure activities fully chatting with friends on phone through the social media, accessing new sites, playing games all confirmed $100 \%$ aided through the internet [39]. Despite the strengthening of the above leisure being assisted through the use of internet, respondents confirmed that hiking as a leisure activity was not aided by the internet, it had $0 \%$ (Table 7 ).

Time taken on preferred leisure activities: The study analysed time spent by the respondents on their preferred leisure activities. The results show that chatting on phone took most time with $38 \%$ spent at 2-4 hrs, followed by accessing sites at 27\% 1-2 hrs, on playing computer games the respondents took 30 minutes to 1 hour at $27 \%$ and lastly those who engaged in hiking as their preferred leisure took the least time at $13 \% 1 \mathrm{~min}$ to $30 \mathrm{~min}$. This suggests that internet aided leisure took the respondents more time compared to the one that is not internet aided as shown below (Table 8).

Satisfaction on time spent on preferred leisure: The study indicated that the respondents were satisfied with the time they spent 
on the leisure activities they engaged in. 144 that is $100 \%$ of respondents confirmed that they were satisfied with the time they spent on their preferred leisure activity. The table below shows the respondents who were satisfied with the time they spent on their preferred leisure activities (Table 9).

Influence of social media: The study suggested that the respondents agreed that social media influenced their perspective towards leisure activities. The results showed that $100 \%$ of the respondents agreed that social media influence their leisure activity while $0 \%$ of the respondents confirmed that social media did not influence leisure activities. This thus confirmed that social media influenced youth respondents' leisure activities significantly as shown below (Table 10).

\section{Discussion of results}

This section of the report dwells on the interpretation of the results of the study.

Media accessed by youth in Rongo university college town campus: According to the study findings, majority of the respondents accessed social media with $100 \%$ of the respondents citing that they normally accessed it. These findings could be attributed to the fact that youth feel more comfortable accessing social media when they are not under supervision. Generally social media has grown rapidly and almost everybody can easily access it. This kind of response by the youth can be attributed to the ever increasing need by the Government of Kenya to make ICT and internet use be easily accessible by the year $2030[40,41]$.

Use of social media to satisfy leisure by youth in Rongo university college: The results in (Table 4) showed that youth used Facebook and Twitter to satisfy their leisure activities and rarely did they engage in active leisure like hiking and playing games. This trend can be attributed to the fact that youth in Rongo University give more time to social media niches compared to the time they give to active leisure. It was also noted that those who gave more time to social media in turn gave little time to active leisure this is evident in stimulation theory that asserts that people need certain level of physical and mental activity. Whenever media content arouses a youth, he or she would like to keep that arousal and pursue excitement through real physical energy [14]. Growth of social media use among youth is increasing yet, little data exist on use of these services in Kenya, and thus from the study it is important to note that youth in Rongo University use social media application extensively [42].

\begin{tabular}{|c|c|c|c|}
\hline \multicolumn{2}{|c|}{ Time } & Frequency & Percent \\
\hline \multirow{5}{*}{$31-30 \mathrm{Min}$} & 29 & 20.1 \\
\cline { 2 - 4 } & $31 \mathrm{Min}-1 \mathrm{hr}$ & 20 & 13.9 \\
\cline { 2 - 4 } & $1 \mathrm{hr}-1 \mathrm{hr} .59 \mathrm{Min}$ & 40 & 27.8 \\
\cline { 2 - 4 } & $2 \mathrm{hrs}-4 \mathrm{hrs} .59 \mathrm{Min}$ & 55 & 38.2 \\
\hline & Total & 144 & 100 \\
\hline
\end{tabular}

Table 8: Time spent on the preferred leisure activities by the respondents.

\begin{tabular}{|l|l|l|l|}
\hline & & Frequency & Percent \\
\hline Satisfaction & Yes & 144 & 100 \\
\hline
\end{tabular}

Table 9: Respondents' satisfaction on time spent with social media.

\begin{tabular}{|l|l|l|l|}
\hline & & Frequency & Percent \\
\hline Influenced & Yes & 144 & 100 \\
\hline & \multicolumn{2}{|l|}{ Table 10: Influence of social media on youth leisure. }
\end{tabular}

\section{Summary of Findings, Conclusions and Recommendations}

\section{Summary of the study}

As deduced from the chapter on results and analysis, social media influenced youth leisure. This means that youth in Rongo University College were adversely influenced by social media. It can be deduced from the above arguments that they could have used social media to satisfy their leisure activities.

Literature review for the study focused on concept of youth and media accessibility and the use of social media to satisfy youth leisure. The chapter ended with a summary of ideas leading to the conceptual framework of the study. The study explored descriptive survey design and the researcher's sample consisted of 144 respondents consisting 64 female and 80 male youth. The researcher therefore designed and developed questionnaires for the respondents. The variables in the questionnaires were tested during the pilot study for content validity and construct reliability. To test for content validity and construct reliability, items were ordered from general to specific and were related to the objectives set for the study. The researcher used Spearman rank order correlation coefficient formula to determine reliability of the instruments. After establishing the content validity and reliability of the instruments that were to be used in the study, the researcher then gave them out to all respondents in the study area, for final data collection. Therefore, the total numbers of respondents who completed and returned the questionnaire were: sixty four (64) female out of the 64 sampled female and eighty (80) male out of the possible 80 . The return rate of questionnaires was 100 percent.

Findings of the study: Findings of the study were presented in accordance with the research objectives of the study.

Media accessed by the youth in Rongo university: The objective of the study was aimed at establishing the media accessed by the youth in Rongo University town campus. The study showed that the respondents accessed various media. The media that respondents from both sexes accessed were: phones, laptops, desktops and ipad. The study realized that both male and female accessed the media.

Use of social media to satisfy youth leisure: The study was set to determine the uses of social media by the youth to satisfy leisure. The study showed that the youth used social media differently to satisfy leisure activities such as: chatting with friends on phone, accessing new sites on Facebook and Twitter and playing video games.

\section{Conclusion}

The following were the conclusions for the study aimed at investigating the influence of social media on youth leisure.

- The data gathered from respondents who participated in the research revealed that youth accessed several media that exposed them to social media.

- The study also concluded that the social media that the youth respondents accessed had great influence on their leisure time

\section{Recommendations}

In light of the findings and conclusions made in this chapter, the researcher came up with a recommendations which if effectively implemented can help the youth to effectively use social media to satisfy leisure time allocated to both active and passive leisure. Youth should look for legislation which governs the use of social media in 
Citation: Nyambuga C, Ogweno J (2014) The Influence of Social Media on Youth Leisure in Rongo University. J Mass Communicat Journalism 4: 223 doi:10.4172/2165-7912.1000223

Page 7 of 7

order to protect them from harmful or unsafe content. The youth should access social media by getting exposed to internet facilities, the youth should also allocate equal time for both active leisure and passive leisure offered by the social media and finally they are supposed to filter social media applications that deny them opportunity in participating in active leisure.

\section{Future Research}

This study is not a complete picture of the influence of social media on youth leisure, yet it provides an impetus for future studies of social media experts'. The data collected gives future researchers a point of research. The adoption of social media influence by media specialists needs much greater examination. More research is needed to gain a better picture of social media activities and youth behaviour as a whole. The influence that the social media has had on youth is not clear.

\section{References}

1. Tam J, Tang WS, Fernando DJ (2007) The internet and suicide: A double edged tool. Eur J Intern Med, 18: 453-455.

2. Safko L, Brake D (2009) The Social Media Bible. Tactics, Tools and Strategies for business Success. John Wiley and Sons. Hoboken, NJ, USA.

3. Oriare $P(2010)$ What the new constitution means for press. Expression Today.

4. Nyabuga G (2011) New Media and its Effects. Nairobi. University of Nairobi press.

5. Valentine G, Holloway SL (2002) Cyberkids? Exploring children's identities and social networks in on-line and off-line worlds. Annals of the Association of American Geographers, 92: 302-319.

6. Boyd DM, Ellison NB (2007) Social network sites: Definition, history, and Scholarship. Journal of Computer-Mediated Communication, 13: 210-230.

7. Ko H, Cho $\mathrm{CH}$ and Roberts MS (2005) Internet uses and gratifications: A Structural Equation Model of Interactive Advertising. Journal of Advertising, 34: $57-70$

8. Kraut R, Patterson M, Lundmark V, Kiesler S, Mukhopadhyay T, et al. (1998) Internet paradox-A social technology that Reduces social involvement and psychological well-being? American Psychologist, 53: 1017-1031.

9. La Ferle C, Edwards SM, Lee WN (2000) Teens' use of traditional media and the Internet. Journal of Advertising Research.

10. Livingstone S (2003) Children's use of the Internet: reflections on the emerging research agenda. New Media \& Society, 5: 147-166, lowa State University Press, Ames, USA.

11. Wrench JS, Thomas-Maddex C, Richmond VP, Mc-Croskey JC (2008) Quantitative research methods for communication: A hands-on approach.

12. Arnett JJ (1995) Adolescents' uses of media for self-socialization. Journal of Youth and Adolescence, Sage Publications, Beverly Hills, USA.

13. Bosch H (2012) Social media and influence among Youths. Bervely Hill: sage

14. Rusell RV (2002) Pastimes: The context of contemporary leisure (2nded.) Champaign, IL: Sagamore.

15. Robinson JP (1969) Television and leisure time: Yesterday, today and (maybe) tomorrow. Public Opinion Quarterly, 33: 210-222.

16. Blumler JG,Katz E (1974) The Uses of Mass Communications: Current Perspectives on Gratifications Research, Sage, Beverly Hills, CA.

17. Lin CA (1999) Uses and gratifications. In: Stone G, Singletary M, Richmond VP (eds) Clarifying Communication Theories: A Hands-on Approach, lowa State University Press, Ames, USA.

18. Comstock G (1991) Television: What's on, who's Watching, and What It Means, Academic Press, San Diego, USA.

19. McQuail D (2005), McQuail's mass communication theory. London: Sage

20. LaRose R, Eastin MS (2004) A social cognitive theory of Internet use and gratifications: Toward a new model of media attendance. Journal of Broadcasting \& Electronic Media 48: 358-377.
21. Gross EF (2004) Adolescent Internet use: What we expect, what teens report Applied Developmental Psychology, 25: 633-649.

22. Valkenburg PM, Soeters KE (2001) Children's positive and negative experiences with the Internet: an exploratory survey. Communication Research, 28: 652 675.

23. Chesley N (2006) Families in a high-tech age: Technology usage patterns, work and family correlates, and gender. Journal of Family Issues, 27: 587-608.

24. Kim ST, Weaver D (2002) Communication Research about the internet: a thematic meta-analysis. New Media \& Society, 4: 518-538.

25. Makanjas O (2011) Internet use by adolescent in Kenya. Nairobi: McMillan Publishers.

26. McKenzie DJ (2011) ICT \& Development in Kenya. Nairobi Penguin Publishers

27. McMillan SJ, Morrison M (2006) Coming of age with the Internet: A qualitative exploration of how the internet has become an integral part of young people's lives. New Media \& Society, 8: 73-95.

28. Barbie (2007) A case study of a community computer center for youth. Journal of New Media \& Society. Sage Publications, Beverly Hills, USA.

29. Morozov E (2009) Iran: downside to the "Twitter revolution". Dissent, 56: 10-14

30. Roberts DF, Foehr UG (2004) Kids and Media in America. Cambridge University Press, Cambridge, UK

31. Mugenda OM, Mugenda AG (1999) Research methods: Quantitative and qualitative Approaches. Nairobi, Kenya: Acts Press.

32. Creswell J (2007) Qualitative Inquiry and Research Design: choosing from among five approaches. Sage Publications Ltd, London.

33. Schramm W (1977) Nature of communication between humans. The Process and Effects of Mass Communication, University of Illinois Press, Urbana, USA

34. Schmidt TS (2006) Inside the Backlash against Facebook. University of Illinois Press, Urbana, USA.

35. Strasburger V, Wilson BJ (2002) Children, Adolescents and the Media. Sage, Thousand Oaks, CA. University of Illinois Press, Urbana, USA.

36. Neuman WL (2006) Social research methods: qualitative and quantitative approaches (6th edn). Boston: Pearson.

37. Lenhart, Amanda, Arafeh, Susan, Smith, et al. (2008) Writing, technology and teens. Pew Internet \& American Life Project.

38. Ellen J (2007) Internet Use by Teenagers. London: Sage Publication.

39. Burns E (2006) Global Internet adoption slows while involvement deepens.

40. Bonfadelli $H$ (2002) The Internet and knowledge gaps: a theoretical and empirical investigation. European Journal of Communication, 17: 65-84.

41. Makinen, Kuira(2012) Internet and ICT application in Kenya. Nairobi: Oxford Publishers.

42. Mangleburg TF, Bristol T (1998) Socialization and adolescents' skepticism toward advertising. Journal of Advertising, 27: 11-21. 